\title{
FUNGOS ASSOCIADOS ÀS SEMENTES DE SERINGUEIRA
}

MIGUEL, Lucas Zambelli Migliaccio ${ }^{1}$

SEGATO, Silvelena Vanzolini ${ }^{2}$

Recebido em: 2015.02.02

Aprovado em: 2015.10.21

ISSUE DOI: $10.3738 / 1982.2278 .1440$

RESUMO: Sementes de seringueira são recalcitrantes, e para manter sua viabilidade precisam conter elevada umidade, a qual, em contrapartida, facilita a proliferação de patógenos. Além de reduzir a qualidade fisiológica da semente, ser o inóculo inicial de epidemias em áreas isenta de patógenos pode depender de sua transmissão via semente. Esse trabalho teve o objetivo de avaliar a sanidade de sementes de seringueira. Utilizaram-se os clones IAN 873 e GT1, os quais foram testados quanto à umidade, germinação e sanidade das sementes recém-coletadas. No clone de maior germinação, repetiram-se as mesmas avaliações após 33 dias de armazenamento sob temperatura ambiente. Nas sementes do clone IAN 873 foram encontrados os fungos dos gêneros Fusarium, Phoma, Aspergillus e Penicillium, enquanto nas sementes do clone GT1 também ocorreram os mesmos gêneros de fungos, além de Colletotrichum.

Palavras-Chave: Hevea brasiliensis. Armazenamento. Sanidade. Germinação

\section{OCCURRENCE OF FUNGI GENERA ASSOCIATED WITH SEEDS OF RUBBER}

SUMMARY: Rubber seeds are recalcitrant, and to maintain their viability the seeds must hold high moisture, which facilitates pathogen proliferation. In addition to reduce physiological quality of the seeds, initial inoculums of epidemics in pathogen-free fields may depend on the pathogen transmission via seeds. This work aimed to evaluate seed sanity of rubber clones. We used the clones IAN 873 and GT1, which were tested for moisture, germination, and sanity in newlyharvested seeds and after 33 days of storage at ambient temperature. In seeds of the IAN 873 clone, fungi from genera Fusarium, Phoma, Aspergillus, and Penicillium were found, whereas in seeds of the GT1 clone the same genera of fungi occurred besides Colletotrichum.

Keyword: Hevea brasiliensis. Storage. Sanity. Germination

\section{INTRODUÇÃO}

A seringueira pertence ao gênero Hevea (família das euforbiáceas) com 11 espécies, das quais Hevea brasiliensis é a mais produtiva e plantada comercialmente com superior qualidade de látex (IAPAR, 2004).

A queda de sementes de seringueira é mais intensa nos meses de janeiro e fevereiro, porém, apresenta variação de um local para outro, durando de dois a três meses entre o início e o final (VALIOIS et al., 1979). Como a maioria das sementes de oleaginosas as sementes de $H$. brasiliensis também têm poder germinativo bastante limitado (CARDOSO, 1980).

Segundo Dijkam, citado por Valiois et al. (1979), sementes colhidas e deixadas ao ar livre apresentam perda de $50 \%$ do poder germinativo depois de 30 dias; aos 50 dias a germinação cai para $10 \%$ e chega a ser

\footnotetext{
${ }^{1}$ Graduando do curso de Agronomia da FE/FAFRAM

${ }^{2}$ Professora doutora, FE/FAFRAM, Ituverava, SP e CUML, Ribeirão Preto, SP
} 
nula em alguns casos. As sementes apresentam um período de viabilidade muito curto, principalmente quando ficam expostas sem qualquer proteção às condições ambientais. Desta forma, a coleta deve ser feita no menor prazo possível após a queda das sementes (CICERO, 1986).

Segundo Vieira et al. (1995) o teste de germinação de sementes de seringueira pode ser conduzido a $30^{\circ} \mathrm{C}$, utilizando-se areia com substrato e avaliação final feita aos 20 dias após a instalação do teste. Ainda relatam que qualidade fisiológica das sementes reduz a partir do primeiro mês de armazenamento. Garcia e Vieira (1994) relatam que o teste de germinação pode ser realizado sob condições ambientais $\left(22-24^{\circ} \mathrm{C}\right)$, com período mais prolongado, para avaliação aos 30 dias.

As sementes de seringueira são classificadas como recalcitrante, ou seja, dotadas de um período de viabilidade muito curto, sendo necessário, portanto, semear logo após a coleta. Além da temperatura, umidade e velocidade de desidratação, os microrganismos também são apontados como um dos principais responsáveis pela perda de germinação das sementes de seringueira. Assim, estas podem ser portadoras de patógenos, os quais, ao disseminarem, atingem as plantas na fase inicial de crescimento ou em fases posteriores. Além disso, são responsáveis pela introdução de patógenos em áreas ainda isentas. Entre os fungos patogênicos à seringueira, já foram relatados em sementes provenientes dos Estados do Pará e da Bahia as seguintes espécies: Botryodiplodia theobromae, Phomopsis sp., Phyllosticta sp., Colletotrichum gloeosporioides, Fusarium sp., Phytophthora sp. e Alternaria sp. Estas espécies causam doenças como o cancro do enxerto, secamento dos ramos, antracnose em folhas e ramos e morte do enxerto, manchas foliares, secamento das raízes e murchas (URBEN et al., 1982).

Silva (2010), ao avaliar a sanidade de sementes de seringueira (clone IAN 873) recém-coletadas e após armazenamento por 34 e 124 dias, encontrou as espécies de fungos infectando as sementes: Aspergillus sp., Botryodiplodia sp., Penicillium sp., Colletotrichum gloeosporioides, Fusarium sp., Macrophomina sp., Pestalotiopsis sp. e Monilia sp.

Há poucos relatos sobre os fungos que as sementes de seringueira podem transportar. Assim, este trabalho teve por objetivo avaliar a sanidade de sementes de seringueira de dois clones (IAN 873 e GT 1) muito usados para porta enxerto.

\section{MATERIAL E MÉTODO}

Local do experimento. $\mathrm{O}$ experimento foi realizado no laboratório de análise de sementes e de Fitopatologia da FAFRAM, em Ituverava, SP.

Coleta, armazenamento e avaliações. As sementes de Hevea brasiliensis Muell. Arg. do clone IAN 873 e GT1 foram obtidas de seringal de cultivo pé-franco, com cerca de 25 anos e 16 anos de sangria, respectivamente, junto à Fazenda Continental, Colômbia, São Paulo. As sementes foram coletadas sob as árvores em 05 de março de 2014, sendo transportadas para o laboratório de análise de sementes da FAFRAM, e no dia 07 de março de 2014 foi instalado o experimento.

Em cada saco de plástico, no qual se acondicionaram as sementes, foram feitos dez furos com uma agulha para permitir trocas gasosas com o meio, conforme foi preconizado por Pereira (1980).

As condições ambientais do laboratório variaram entre 30 a $35^{\circ} \mathrm{C}$ e com umidade relativa do ar de 40 a $48 \%$, monitoradas por termo-higrógrafo para saber as condições ambientais às quais as sementes foram 
submetidas no armazenamento.

As sementes dos clones de seringueira foram avaliadas quanto ao teor de água inicial no dia da execução dos testes e após 33 dias de armazenamento sob temperatura ambiente. Também se realizaram testes de germinação e sanidade nas sementes dos clones recém-coletados e após 33 dias de armazenamento em condições de laboratório. Contudo a germinação e sanidade após o armazenamento foi realizado somente para o clone que apresentou maior germinação. Os testes foram conduzidos em delineamento inteiramente casualizado e as repetições descritas nas metodologias dos testes.

Caracterização inicial dos clones. Teor de água (TA). Foi determinado o teor de água dos clones assim que chegaram as sementes e no dia da instalação dos testes, pelo método da estufa, a $105 \pm 3^{\circ} \mathrm{C}$ por 24 horas, segundo as Regras para Análise de Sementes (RAS) (BRASIL, 2009). Foram utilizadas dez repetições constituídas de cinco sementes para cada clone de seringueira. Os resultados foram expressos em porcentagem (base úmida).

Teste de germinação (TG). Essa determinação foi realizada em caixas plásticas com dimensões de 26 × 16 × $9 \mathrm{~cm}$, utilizando-se vinte repetições constituídas de 10 sementes em areia de textura média, umedecida inicialmente com 60\% de sua capacidade de retenção de água (BRASIL, 2009) e re-umedecidas sempre que necessário. As sementes foram distribuídas uniformemente com ajuda de um gabarito a $3 \mathrm{~cm}$ de profundidade e cobertas com areia umedecida. As caixas foram mantidas em um germinador a $30^{\circ} \mathrm{C}$, e foram cobertas com sacos plásticos para manter a umidade. Logo após o início da germinação retirou-se o saco de plástico. Aos 30 dias após a instalação do teste (VIEIRA et al., 1995; SILVA, 2010), o número de plântulas emersas (considerou-se como emersas aquelas que apresentaram o ápice do epicótilo acima da superfície da areia) foi computado para cada repetição, obtendo-se a porcentagem média de germinação de cada clone de seringueira.

Sanidade - blotter test. Para o teste de sanidade, optou-se pelo teste do papel de filtro (Blotter Test). O teste foi realizado com 200 sementes de cada clone, as quais foram divididas em 10 sementes por caixa Gerbox. As caixas foram forradas com papel filtro umedecido, na qual foram colocadas as sementes. As caixas foram fechadas com suas tampas e levadas para uma estufa, e ali permanecendo por 10 dias a $20^{\circ} \mathrm{C}$, utilizando-se um regime intermitente de 12 horas de luz e 12 horas de escuro. Após esse período, as caixas Gerbox foram retiradas da estufa e as sementes dos clones de seringueira foram avaliadas com o auxílio de um microscópio estereoscópico para verificar a incidência de fungos. Quando necessário foram examinadas lâminas sob um microscópio composto.

\section{RESULTADO E DISCUSSÃO}

Os dados da Figura 1 mostram a caracterização dos clones quanto ao teor de água das sementes e porcentagem de germinação. As sementes de seringueira coletadas já chegaram ao laboratório com teor de água baixo, provavelmente por terem sido coletadas após algum tempo de sua queda das árvores. Segundo Valiois et al. (1979), a queda de sementes de seringueira é mais intensa, em geral, nos meses de janeiro e fevereiro. No entanto, apresenta variação de um local para outro, com duração de dois a três meses entre o início e o final da dispersão. As sementes usadas nesse experimento foram coletadas em março, portanto com 
chance de terem sido expostas a condições adversas do ambiente que poderiam levar a queda na qualidade fisiológica das mesmas.

Embora Cardoso (1980) afirme que o poder germinativo das sementes de seringueira seja bastante limitado, a baixa umidade encontrada nas sementes de seringueira, que são recalcitrantes, resultou em germinação (Figura 1) também baixa, 27 e 48\% para os clones IAN 873 e GT1, respectivamente.

Figura 1. Caracterização de sementes dos clones de seringueira quanto à porcentagem de germinação inicial (Gi) e teor de água (\%) no momento da coleta das sementes (TA chegada) e durante a implantação (TAi) do teste de germinação e sanidade. Ituverava, SP. 2014.

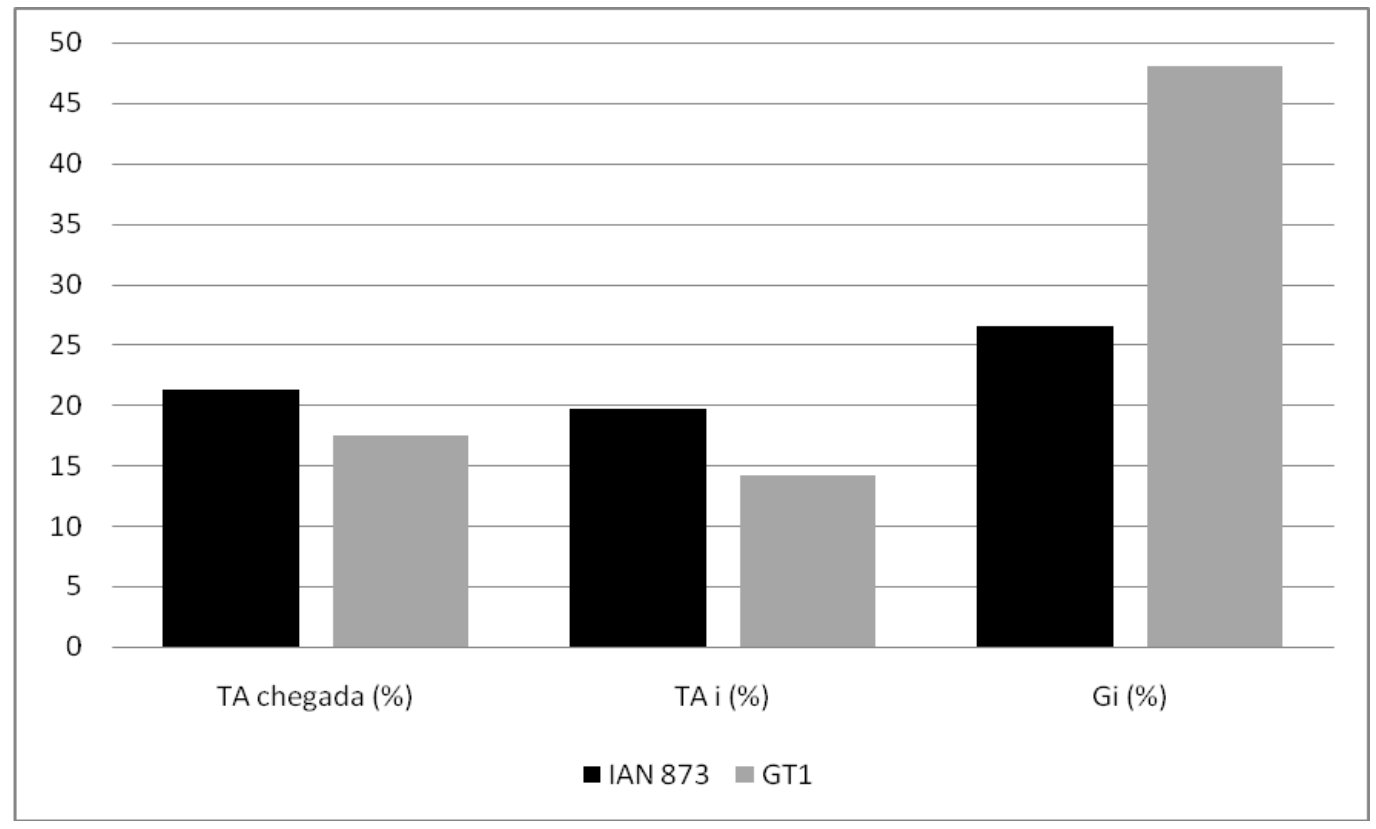

Fonte: Elaborado pelo autor

Os fungos encontrados nas sementes recém-coletadas de ambos os clones de seringueira pertenceram aos gêneros: Fusarium, Phoma, Aspergillus e Penicillium (Figura 2). O fungo Colletotrichum sp. foi encontrado apenas nas sementes do clone GT1. Os fungos Fusarium sp., Colletotrichum gloeosporioides já foram relatados por Urben et al. (1982) e Silva (2010) em sementes de seringueira. Silva (2010) também relatou os fungos Aspergillus sp. e Penicillium sp. nas sementes dessa espécie.

A baixa porcentagem de germinação das sementes do clone IAN 873 no início do experimento (Figura 1) motivou apenas manter o clone GT1 para ser reavaliado após 33 dias de armazenamento (Figura 3).

A germinação das sementes do clone GT1 após 33 dias de armazenamento em condições de laboratório foi nula, e a umidade das sementes foi de 10,3\% (dados não apresentados).

Após o armazenamento das sementes, a ocorrência dos gêneros de fungos foi praticamente a mesma, com exceção do gênero Colletotrichum, que não estava mais presente nas sementes (Figura 3). De fato, Machado (2000) relata que sementes contaminadas ou infectadas no campo podem ter sua sanidade alterada durante o armazenamento, devido à perda de viabilidade dos patógenos. 
Figura 2. Incidência de fungos (\%) em sementes recém-coletadas de dois clones de seringueira. Ituverava, SP. 2014.

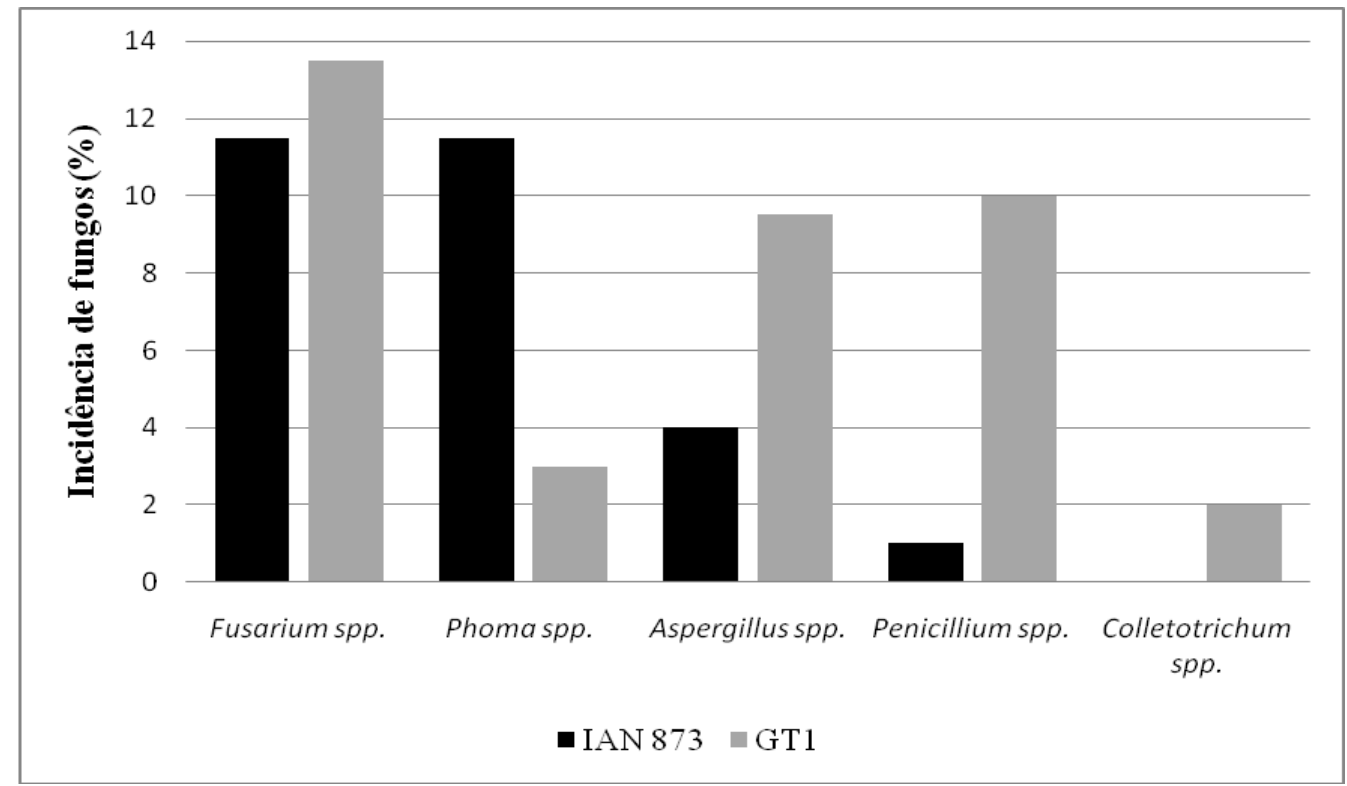

Fonte: Elaborado pelo autor

Vale a pena destacar a alta incidência de Fusarium sp., que aumentou de 13,5\% para 51,5\%. Phoma sp. e Aspergillus sp. também tiveram sua incidência aumentada nas sementes armazenadas após 33 dias (Figura 3).

Figura 3. Incidência de fungos (\%) em sementes do clone GT1 recém-coletadas (inicial) e armazenadas (final) em condição de laboratório. Ituverava, SP. 2014.

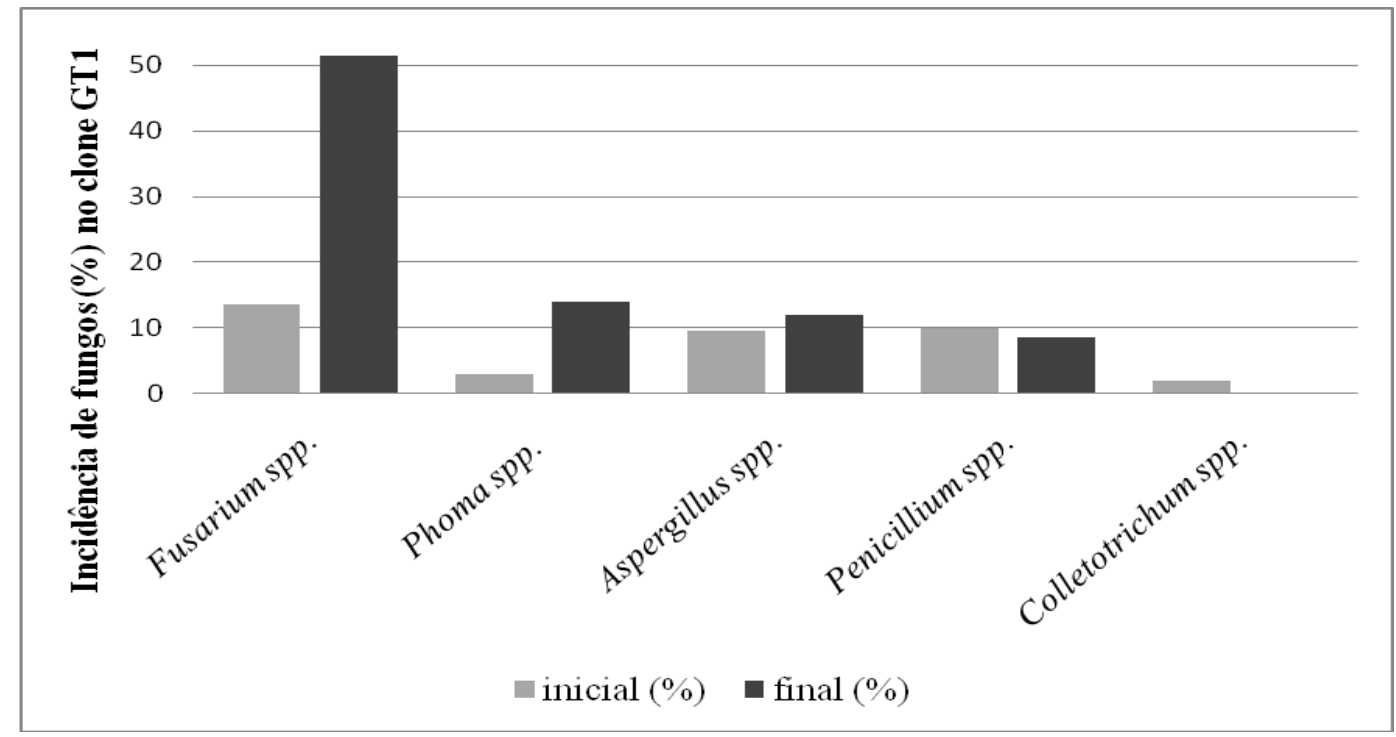

Fonte: Elaborado pelo autor 
Essa alta taxa de contaminação por fungos, aliada à baixa umidade das sementes explicam o porquê as sementes de seringueira não germinaram após o armazenamento por pouco mais de 30 dias em condições de laboratório.

\section{CONCLUSÃO}

Nas sementes de seringueira do clone IAN 873, os fungos encontrados pertenceram aos gêneros Fusarium, Phoma, Aspergillus e Penicillium, enquanto nas sementes do clone GT1 também ocorreram os mesmos gêneros de fungos, além de Colletotrichum.

\section{REFERÊNCIAS}

BRASIL. Ministério da Agricultura Pecuária e Abastecimento. Regras para análise de sementes. Brasília: MAPA/ACS, 2009. 399 p.

CARDOSO, M. Instrumentação para a cultura da seringueira. 2. ed. Campinas: Instituto Agronômico, 1980. 42 p. (Boletim 196).

CICERO, S.M. Produção, coleta, transporte e armazenamento de sementes de seringueira. EsalqPiracicaba. Capítulo 8, p.133-137. 1986

GARCIA, A; VIEIRA, R.D. Germinação, armazenamento e tratamento fungicida de semente de seringueira (Hevea brasiliensis MUELL. ARG.). Revista Brasileira de Sementes, v.16, n.2, p.128-133, 1994. http://www.abrates.org.br/revista/artigos/1994/v16n2/artigo05.pdf. Acesso em: 05 mar.2015

IAPAR- INSTITUTO AGRONOMICO DO PARANÁ. O cultivo da seringueira (Hevea spp.). Secretaria do Estado da Agricultura e do Abastecimento. 22 nov. 2004. Disponível em:

<http://www.iapar.br/arquivos/File/zip_pdf/cultsering.pdf>.Acesso em: 05 mar. 2015

MACHADO, J.C. Patologia de sementes: significado e atribuições. In: CARVALHO, N.M.; NAKAGAWA, J. Sementes: ciência, tecnologia e produção. 4. ed. Jaboticabal: FUNEP, 2000. 588 p.

PEREIRA, J. da P. Conservação da viabilidade do poder germinativo da semente de seringueira. Pesquisa Agropecuária Brasileira, Brasília, v. 15, n.2, p.237-244, 1980.

SILVA, R.A. Qualidade fisiológica e sanitária de semente de seringueira armazenadas em diferentes ambientes. 2010. 39 f. Trabalho de Conclusão de Curso (Graduação em Agronomia) - Faculdade Dr. Francisco Maeda. Fundação Educacional de Ituverava.

URBEN, A.F; WETZEL, M.M.V.S; CÍCERO, S.M. Ocorrência de fungos em sementes de seringueira. Pesquisa Agropecuária Brasileira, Brasília, v.17, n.10, p. 1633-1637, 1982.

VALIOIS, A.C.C. et al. Cultura da seringueira. Norte Brasília, 1979. 218 p. (Manual técnico, 9).

VIEIRA, R.D; BERGAMASCHI, M. C. M; MINOHARA, L. Qualidade fisiológica de sementes de seringueira (Hevea brasiliensis MUELL. ARG.) tratadas com benlate durante o armazenamento. Scientia Agricola, Piracicaba v. 52, n. 1, p. 151-157, 1995.

Nucleus, v.12, n.2, out.2015 